\title{
Computational fluid dynamics study of primary parallel fan stations
}

\author{
G Reyes Universidad de Santiago de Chile, Chile \\ JP Hurtado Universidad de Santiago de Chile, Chile \\ JP Vargas Universidad de Santiago de Chile, Chile \\ El Acuña Universidad del Desarrollo, Chile
}

\begin{abstract}
A computational fluid dynamics (CFD) study was developed considering primary parallel fan stations that are currently in operation within Chilean mines. A set of three station designs were considered, and the CFD modelling was used to simulate the operating points of the fan curves comparing operating performance in terms of airflow pressure and energy consumption. This approach allowed for the identification of the best primary fan configuration based on resistance curve and energy consumption relating to the fan station geometry. To standardise the comparison between the different stations, the same primary fan was used in all the simulations at the same fixed blade angle and speed setting. The simulation implemented the use of three-dimensional models, based on two-dimensional prints, considering $7.2 \times 7.2 \mathrm{~m}$ cross-section headings. Five resistance values were obtained reflecting the fan operating points; one for each geometry, which were then used to identify which model presented the best fan performance. This paper presents the results obtained through the CFD simulations and the corresponding operating points of primary fans. The results are discussed taking into account pressure, velocity and vector contours to understand the fluid dynamics phenomena occurring inside the station. The best-performing station geometry was identified based on the lowest frictional and shock pressure losses, highest airflow delivery and lowest energy cost.
\end{abstract}

Keywords: parallel fan stations, computational fluid dynamics, underground ventilation design

\section{Introduction}

Operators of underground mines would like to increase production rates, to make the business more competitive by offsetting increased costs from the depletion of surface deposits and the greater depth of new deposits. This can lead to the need for more and larger diesel equipment working inside the mine. As a result, the need to supply fresh air to the work face increases, as well as the required capacity to extract the return air.

Parallel fan stations are used when the amount of air needed inside the mine is of such a magnitude that one fan fails to meet this need, or an additional fan is required to cover maintenance periods. Fans installed in galleries arranged in parallel allow the generation of a similar pressure in both fans, such that they work under similar demand conditions sharing the pressure and airflow load. Also, if one of the fans is down for maintenance, the other one alone can usually supply around $70 \%$ of the total airflow volume when both are working (McPherson 2009). In the past, modelling of parallel fan station performance has been performed using analytical and ventilation software tools. In recent years, computational fluid dynamics (CFD) has been used for modelling areas of interest within ventilation models, in particular, unsmooth geometries such as fan stations (Hurtado \& Acuña 2015).

According to Versteeg and Malalasekera (1995), CFD is the analysis of systems involving fluid flow, heat transfer and associated phenomena such as chemical reactions by means of computer-based simulation. Previously, the application of CFD has been proposed for the simulation and comparison of shock losses in underground mine ventilation systems (Isidro et al. 2010). CFD simulation has also been applied to 
ventilation shock losses in production drifts (Acuña et al. 2014) and to parallel fan stations (Hurtado \& Acuña 2015). However, the results were not definitive since the conditions evaluated were for a single geometry. In these works, the authors provided the theoretical basis and conditions for simulation of parallel fan stations with CFD. More work is required to understand the variation of the fan performance depending on the station geometry design.

The study of the parallel fan ventilation stations developed in this paper considers three different geometries currently in use for underground mining in Chile. Due to the heterogeneity of their construction, it was necessary to establish the dynamic fluid characteristics of each design, so as to discuss the advantages or disadvantages of each fan station configuration and then determine the most energy efficient one.

This paper presents guidelines as to the geometry characteristics that need to be considered for parallel ventilation stations containing two fans, for three particular designs. The designs are compared according to fan operating points, energy consumption and differences in the systematic resistance they present under standard conditions.

\section{Methodology}

The three two-fan parallel ventilation station geometries are modelled and simulated with a computational fluid dynamic software to determine the fans' operational points. The objective was to find out which geometry had a fan operating point with higher flow rate and lower static pressure, indicating the lowest resistance under the same conditions.

In order to perform a dynamic fluid comparison of the stations, it is necessary to establish some similar characteristics in the models. This is why a standardised fan was used for all configurations. The fan selected was an axial fan, model Alphair 1480 AMF 6600, with the blade angle set to $20^{\circ}$, an impeller diameter of $4 \mathrm{~m}$, equipped with an inlet bell on the suction and a diffuser on the discharge side, a maximum flow of $470 \mathrm{~m}^{3} / \mathrm{s}$ and 1,890 Pa maximum pressure (as per Hurtado \& Acuña 2015). As the resistance of the galleries depends on their geometric characteristics, a common cross-sectional airway area was used for all models, namely $7.2 \times 7.2 \mathrm{~m}$. Figure 1 shows the fan's characteristic curves for its range of blade angles (Figure 1(a)) and the individualised flow curve (red) and power (blue) selected for the fan with a $20^{\circ}$ blade setting angle (Figure 1(b)).

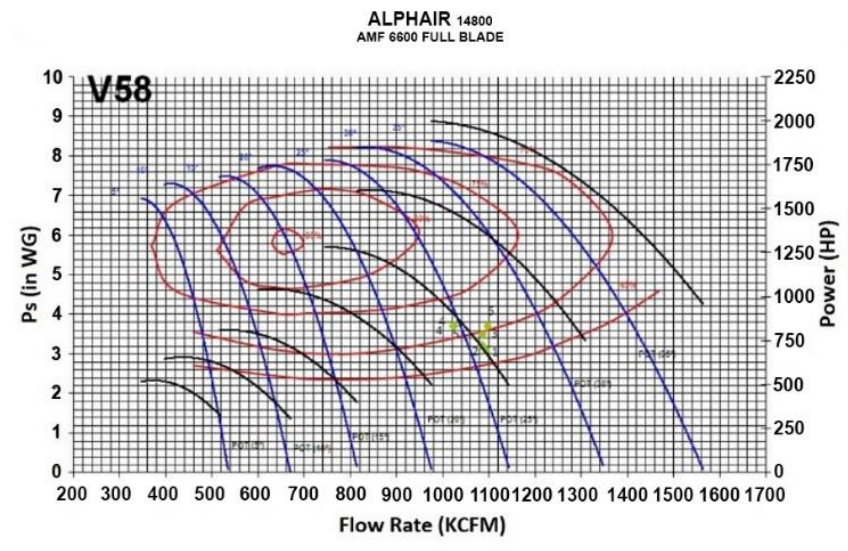

(a)

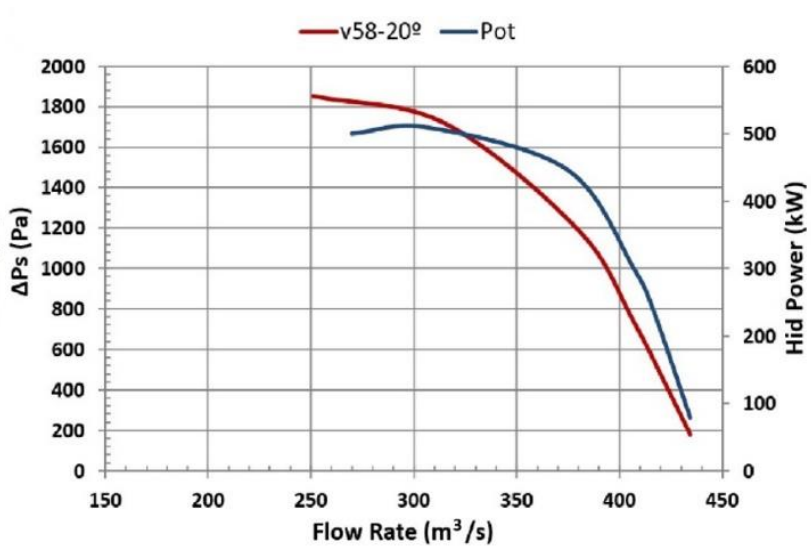

(b)

Figure 1 (a) Fan characteristic curves; and, (b) CFD Calibrated and simulated fan curve and hydraulic power curve for a $20^{\circ}$ blade angle 


\section{$3 \quad$ Studied geometries}

The three parallel fan ventilation station configurations considered in this study were named as follows:

- Parallel branches or symmetrical branches (SB) (Figure 2).

- Displaced branches or overlapped branches (OB) (Figure 3).

- Bypass or run around (RA) (Figure 4).

\subsection{Symmetrical branches}

This model consists of four singularities: two $30^{\circ}$ elbows per branch, one ' $Y$ ' opening, one ' $Y$ ' joint $\left(60^{\circ}\right.$ each). In addition, the station has a central gallery to allow for personnel or vehicle movement (vehicle bypass), which is truncated for simplicity reflecting that there are ventilation doors that prevent recirculation. This configuration presents a total construction length of $517 \mathrm{~m}$, and is based on the layout used at the El Teniente mine. In this analysis, only the centre lines were considered for the construction of the fan station geometrical model. The actual mine layout had different size galleries and fans. The physical characteristics of the model are illustrated in Figure 2.

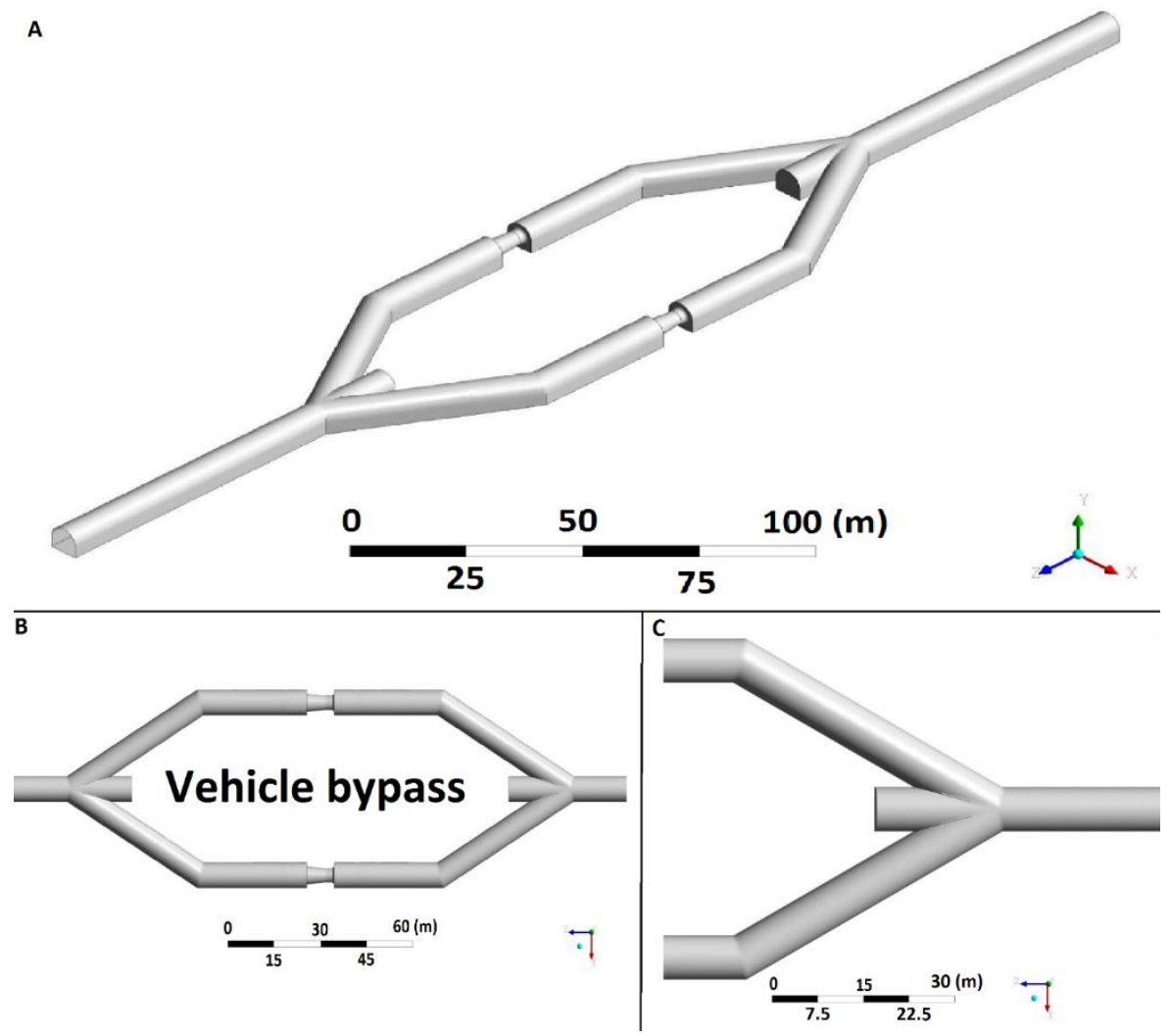

Figure 2 Symmetrical branches ventilation station 3D model; (a) Isometric view; (b) Plan view; and, (c) Plan view close-up of branch intersection 


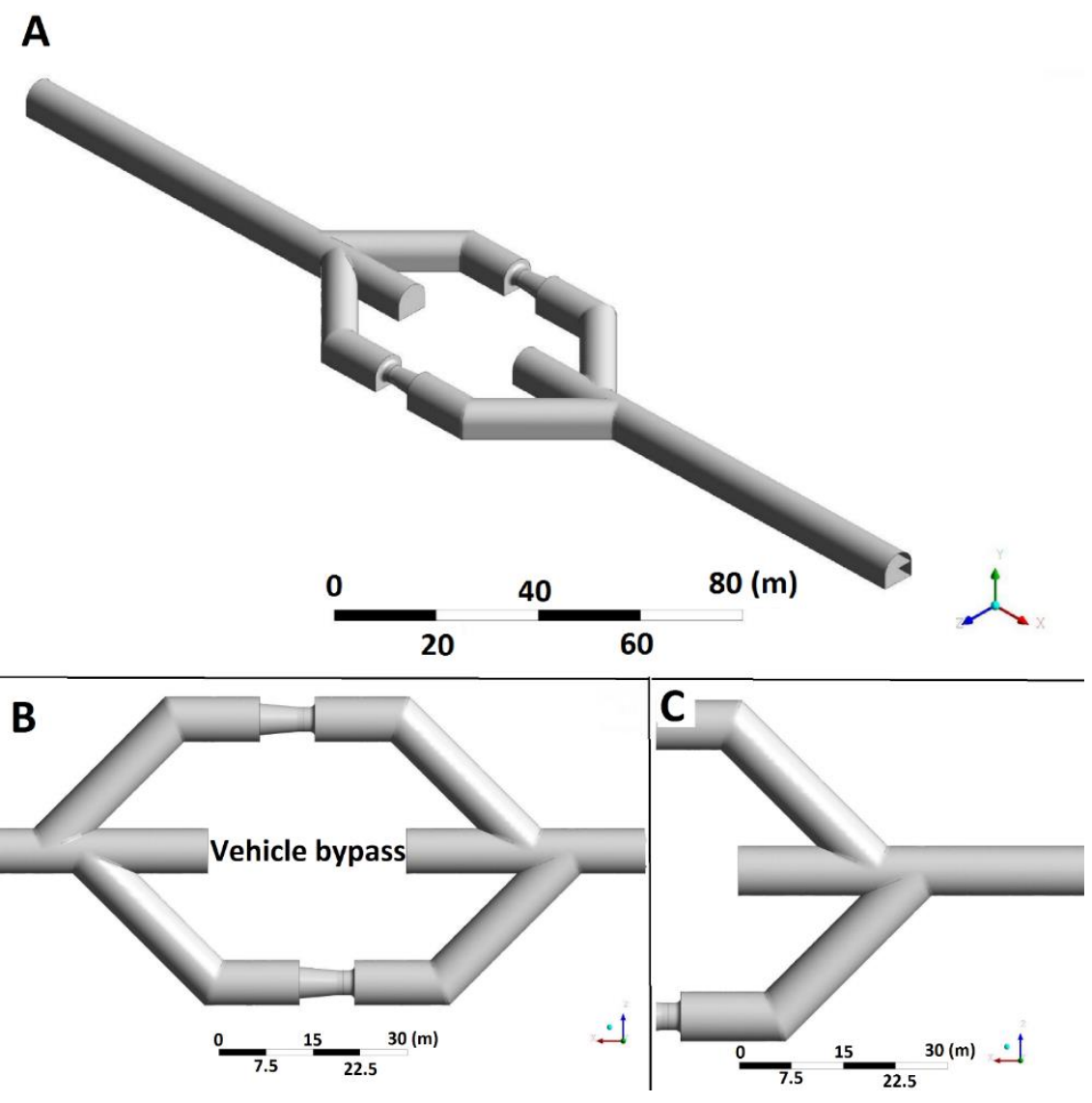

Figure 3 Displaced branch station 3D model; (a) Isometric view; (b) Plan view; and, (c) Plan view close-up of branch intersection

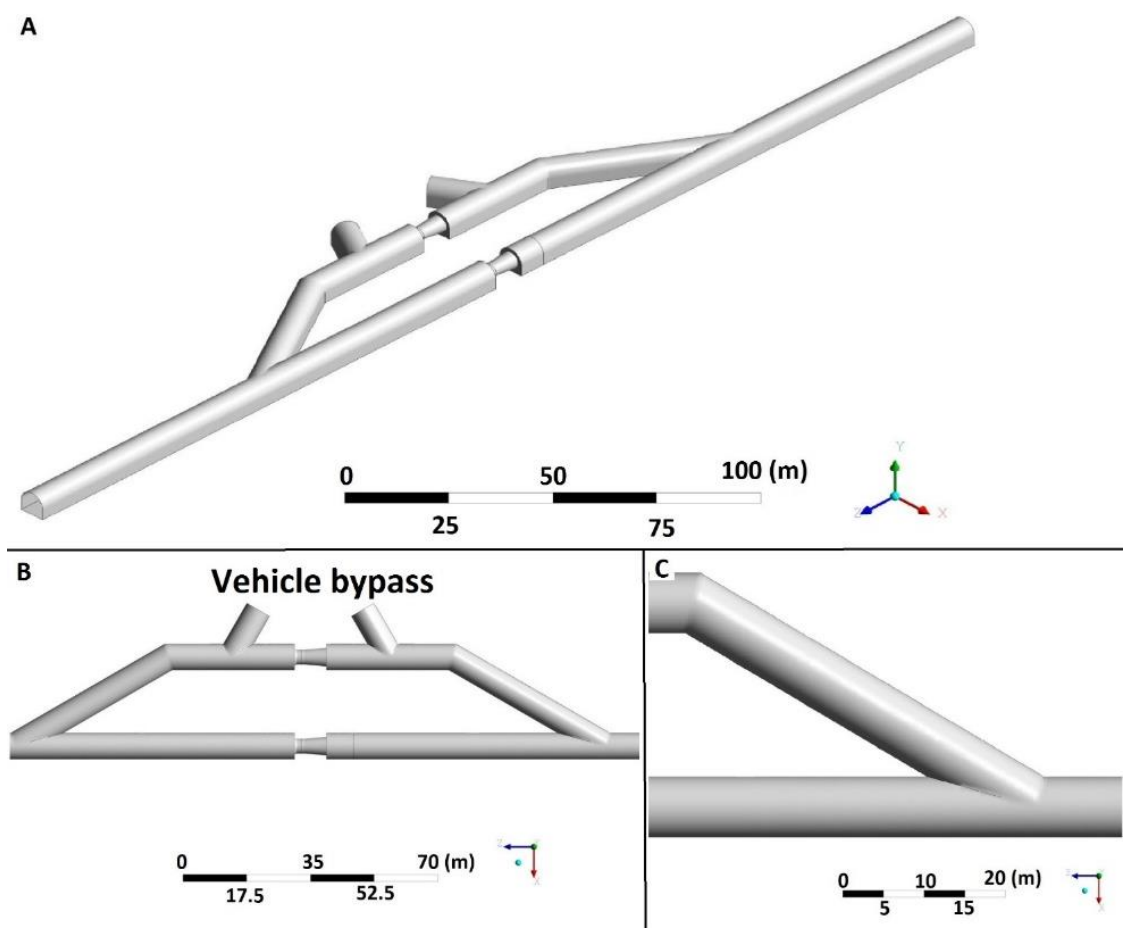

Figure 4 Run around station 3D model; (a) Isometric view; (b) Plant view; and, (c) Close-up of branch intersection 


\subsection{Overlapped branches}

This configuration is very similar to the parallel branches, but it has the peculiarity that the union and separation of the branches are displaced by $6.5 \mathrm{~m}$ and its angle of union is $45^{\circ}$ from the centre line. This geometry in turn also presents the transit gallery through the middle of the ventilation station.

This station has a construction length of $379 \mathrm{~m}$, which makes it the shortest ventilation station arrangement studied. It presents more abrupt singularities and shorter distances for flow stabilisation leading to and from the fan.

\subsection{Run around (bypass)}

This configuration consists of two $30^{\circ}$ elbows, a separation, and a union also at $30^{\circ}$. The station comprises $479 \mathrm{~m}$ of gallery constructed between branches. The gallery for vehicle and pedestrian traffic is an additional bypass with control doors further from one side. This configuration was designed and studied previously by Hurtado and Acuña (2015) for the New Level Mine project for El Teniente mine. It was proposed as a solution for the ventilation design to achieve the airflow volume requirements during the development phase.

\section{$4 \quad$ Boundary conditions}

Boundary conditions are a necessary component for mathematical fluid dynamics models because they direct the movement of the flow and can assign properties as basic as the state of matter, solid or liquid, and establish the type of material, velocities, and pressures, among other parameters. In this study, we used three main boundary conditions: fan, outlet vent and wall. The fan edge condition assigns the fan characteristic curve to a surface (3D models) by means of defined points with average speed and static pressure.

Outlet vent basically functions as an obstruction surface or line (for 2D) to which a flow resistance is assigned (orifice plate type), and regulated by the coefficient of loss $k$, which is proportional to such obstruction. This condition is used in the input (inlet) and outlet (geometry), which allows for adjustment of the operating point of the fan by changing the coefficients of loss $k$.

The walls are used to delimit the region of the fluid and that of the solid, representing any type of solid wall present in the geometry. In viscous flows, the tangential velocity of the fluid is equal to the standard condition wall, and the velocity in its normal component is zero. The wall condition is used to assign a roughness to the walls of the fan stations, which for this study is the same for all drifts. Figure 5 shows the boundary conditions' location in the geometry.

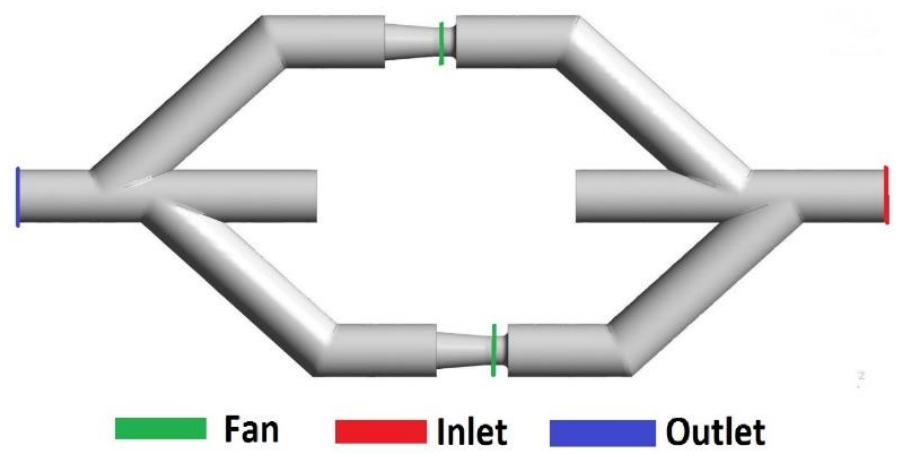

Figure 5 Boundary condition location 


\section{$5 \quad$ Initial conditions}

The initial conditions are the physical characteristics of the stations in the simulation. In this case, the resistance of the system is varied, whereas the aforementioned variables are defined by default as ideal conditions at $15^{\circ} \mathrm{C}$ and atmospheric pressure of 101,325 Pa. The loss coefficients ' $X$ ' to define the resistance of the system are defined as a shock loss factor, which is shown in the following formulae:

$$
\Delta P=X \frac{1}{2} \rho u^{2}
$$

where:

$$
\begin{aligned}
& u \quad=\text { velocity. } \\
& \rho \quad=\text { density of air. }
\end{aligned}
$$

In Table 1, the loss coefficients for fan ventilation stations to set the operating point are shown.

Table 1 Loss coefficients for fan ventilation stations

\begin{tabular}{ll}
\hline $\boldsymbol{X}_{\text {entry }}$ & $\boldsymbol{X}_{\text {outlet }}$ \\
\hline 7.5 & 15 \\
7.5 & 7 \\
0 & 6.5 \\
0 & 3 \\
0 & 0 \\
\hline
\end{tabular}

' $X$ ' values presented in Table 1 are used to replicate upstream and downstream resistance simulating different operating points. For practical case analysis, the mid-point of the fan operational curve has been selected as the initial operation condition. This point was chosen because it is far from the stagnation zone and is also located in an area with an approximate efficiency of $70 \%$.

\subsection{Obtaining the operational point}

In order to describe the operation points of the fan stations, the static pressure (McPherson 2009) was used, where Figure 6 is obtained according to the following Equation 2.

$$
P_{\text {fan static }}=P_{\text {total inlet(1) }}-P_{\text {static outlet(2) }}
$$

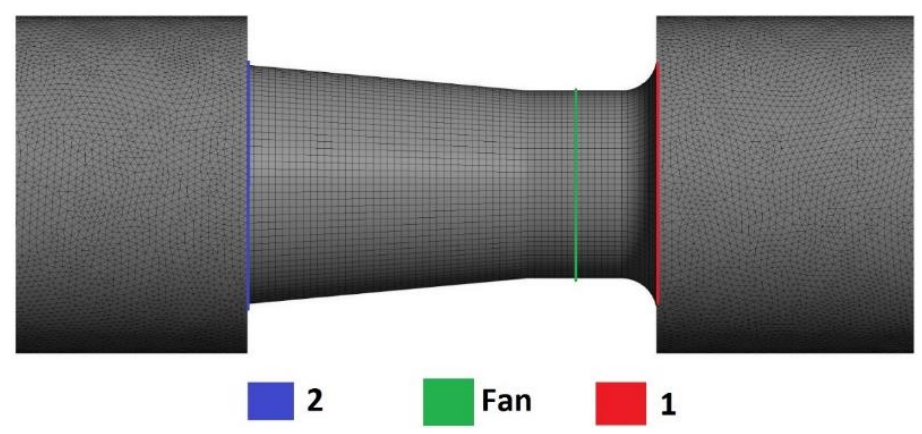

Figure 6 Static, dynamic and total pressure measurement for a fan in booster mode 
The flow rate was established directly at the fan outlet via a control surface (Figure 6, blue line). In addition, each fan was identified according to the position and direction of flow. In the plan view of the fans, the flow direction runs from left to right. Figure 7 shows the flow direction and fan arbitrary naming convention. The top one is 'fan a' and the bottom one 'fan b'.

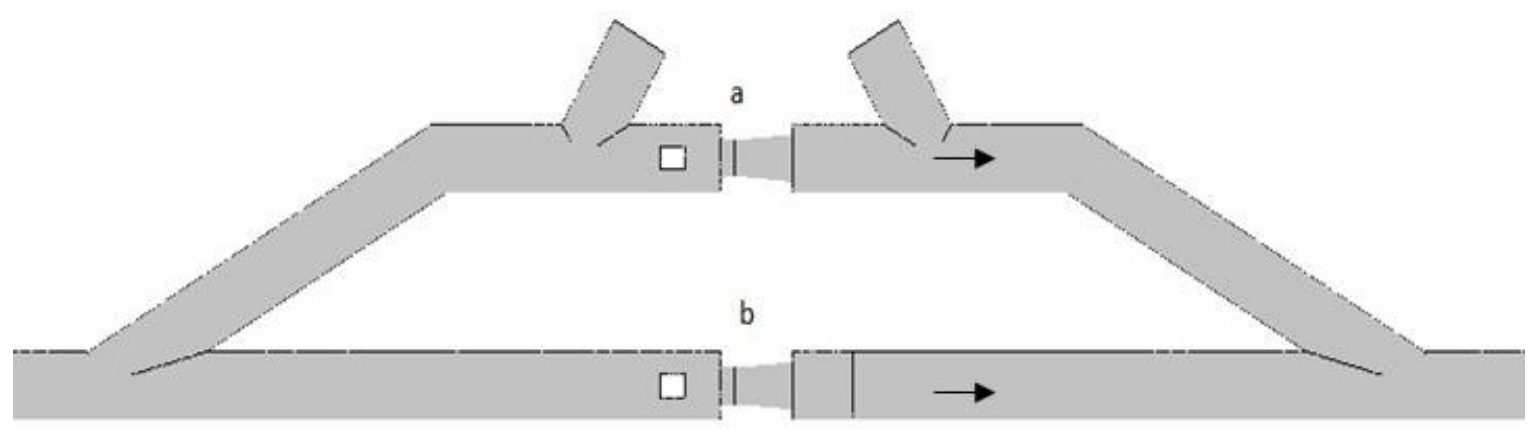

Figure 7 Fan naming according to airflow direction

\subsection{Mesh}

The cell size for the fan zones and in its vicinity corresponds to a $10 \mathrm{~cm}$ cell size. In the drifts, it was defined as constant $50 \mathrm{~cm}$ for the stations, obtaining an approximate total of six million cells (Figure 8).
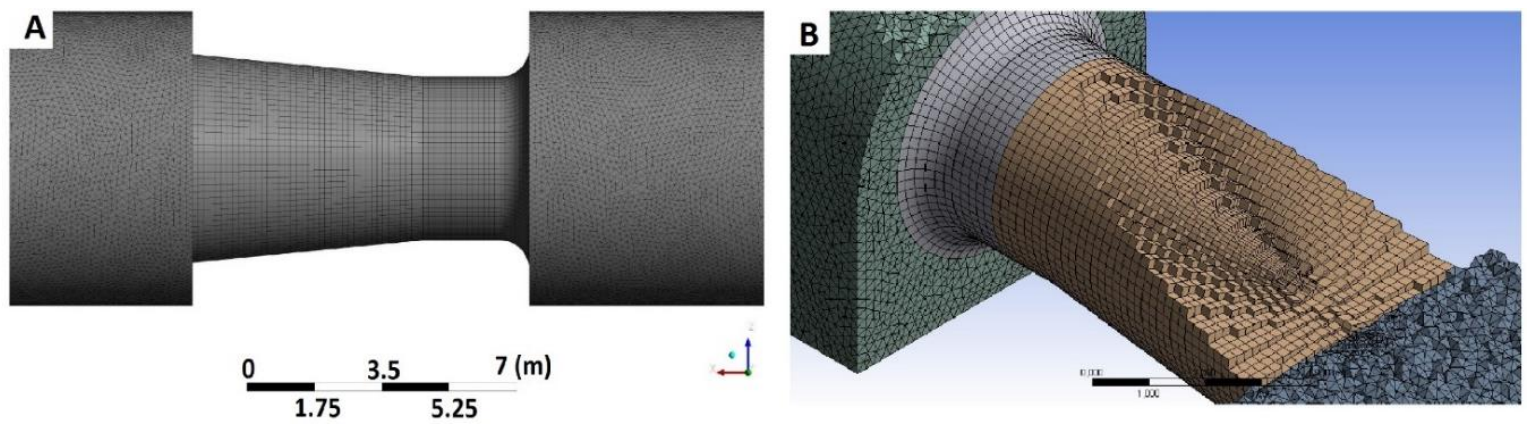

Figure 8 Mesh in fan zone

\section{$6 \quad$ Results}

\subsection{Operational points}

Table 2 shows the operational points for the symmetrical branches, overlapped branches and run around configurations at different resistance points of the ventilation system with their respective operation graph in Figure 9.
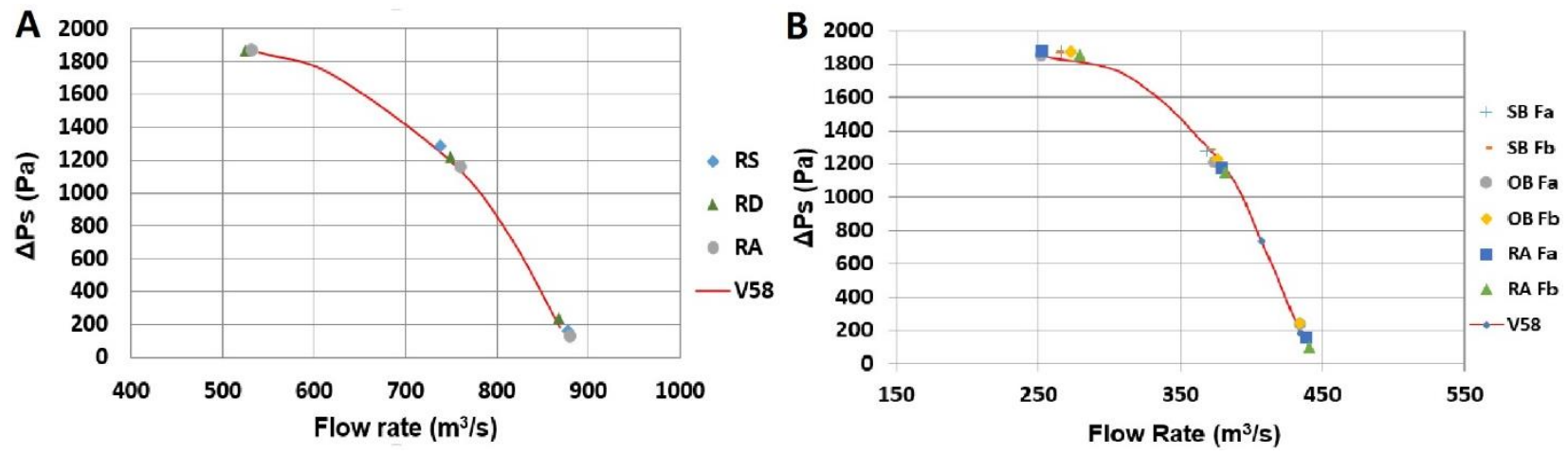

Figure 9 (a) Ventilation station characteristic curve comparison; and, (b) Individual fans 
Table 2 Operational points for studied fan ventilation station geometries

\begin{tabular}{llllllllll}
\hline \multicolumn{9}{c}{ Fan a } & \multicolumn{2}{c}{ Fan b } & \multicolumn{2}{c}{ Total } & Hydraulic \\
power (kW)
\end{tabular}

To compare the different configurations, common resistance states $(7.5-15,0-6.5$ and $0-0)$ are defined in Figure 9, where Figure 9(a) represents the total flow and pressure of the stations, while Figure 9(b) represents the fans individually.

To centre the comparison, the average resistance of the curve with edge condition $X_{\text {inlet }}=0$ and $X_{\text {outlet }}=6.5$ is used. The results are shown in Figure 10 where the operating point of the fans within the stations is compared. It can be observed that the operating point of the run around configuration is the geometry with higher flow and lower pressure, followed by the overlapped branches configuration. Figure 11 allows one to observe the resistance curves for the three configurations under the boundary condition of medium resistance, with a clear differentiation in its curve of total resistance for each station. Figure 11(a) shows the complete curve of the fan, and Figure 11(b) shows an approach to the operating points of each fan configuration. 


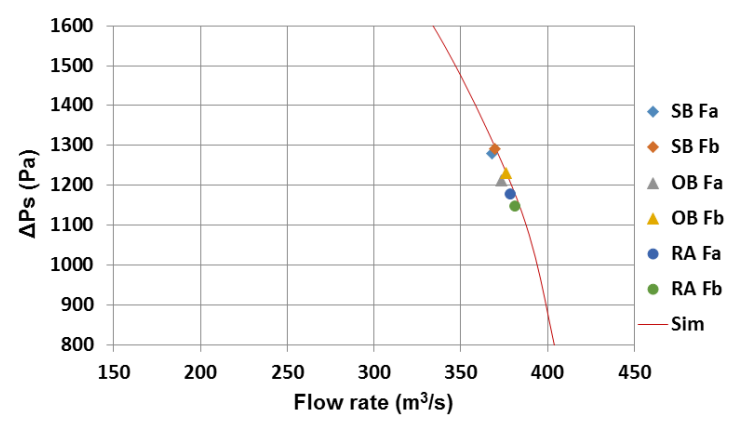

Figure 10 Close-up of operational points $\left(X_{\text {entry }}=0, X_{\text {outlet }}=6.5\right)$
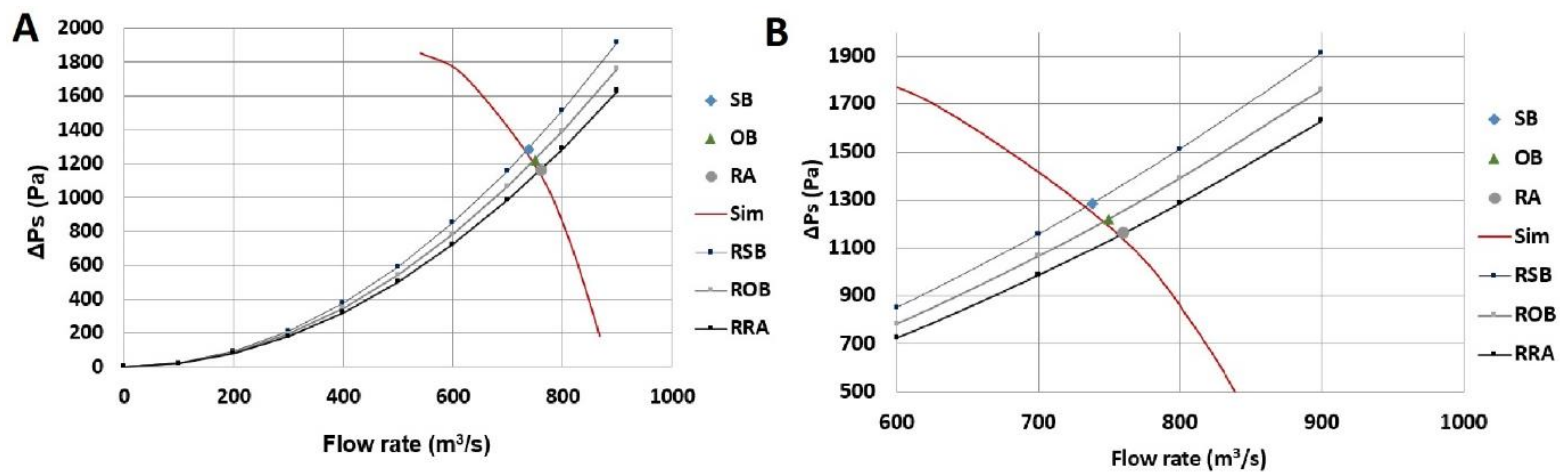

Figure 11 System resistance curve comparison based on station geometry

\subsection{Computational fluid dynamics analysis}

Figures 12 and 13 respectively show the velocity vectors, given in plan view, for each fan station and for the separations and junctions of the flow, according to each configuration. The block on the left side of each plot represents the fan motor. Figure 14 shows a full plan view of the velocities through each station configuration. Similarly, a static pressure plan profile is shown in Figure 15 for each complete configuration. From these figures, it can be observed that the flow entering some of the fans is unbalanced due to the upstream singularities such as the separations, elbows and their interactions, which affects the point of operation of each fan. The fan with the best operating point and higher flow rate is ' $f a n b^{\prime}$ ' of the run around configuration. This is because this fan has one distant separation of $70 \mathrm{~m}$ upstream, which allows the flow to fully develop before entering the fan. A close inspection of the run around 'fan a' velocity vector in Figure 12 (RA a) shows that it has double equally sized vortices downstream from the motor assembly indicating a relatively homogenous flow entering from both sides of the fan inlet. The remaining fans in Figure 12, including 'fan b' of the run around arrangement, show varying levels of inhomogeneity in the flows entering the fans. The flow through 'fan a' of the run around configuration has to travel a longer distance and go through two counter elbows, but it appears to help ordering the airflow stream before entering the fan. This is evident in Figure 16 where the coloured velocity vectors are shown according to a bounded velocity scale to show differences in the drift flow velocity prior to entering the fans. Apparently, the two singularities (elbow and counter elbow) prior to the 'fan a' entry allow the airflow to properly align, whereas in 'fan b', the flow does not reach the same level of alignment. It is important to notice that it is a three-dimensional simulation, and the vortices involved have an important vertical component. 

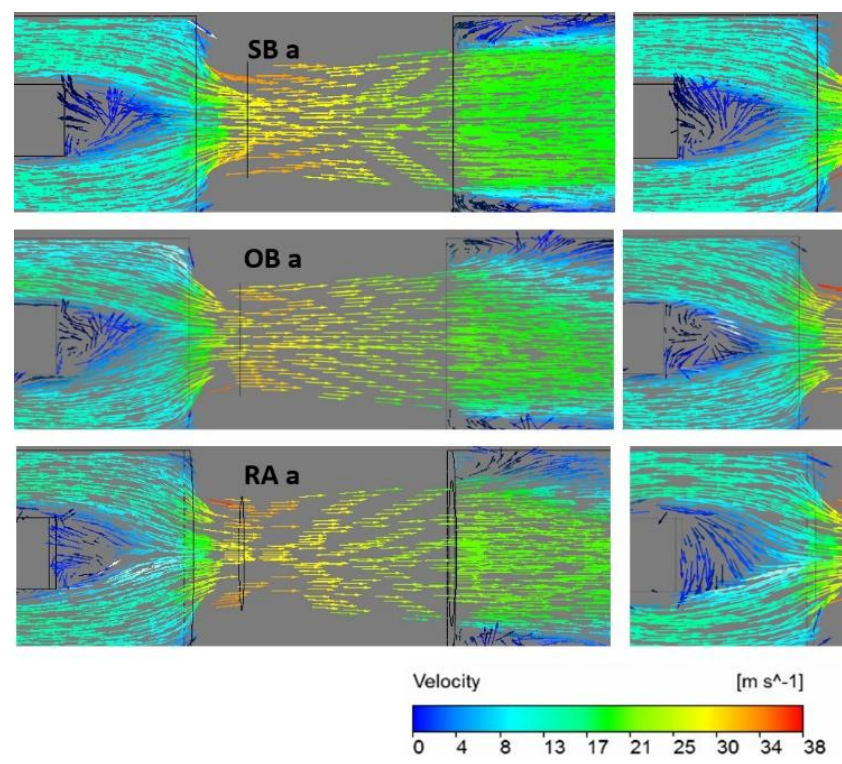
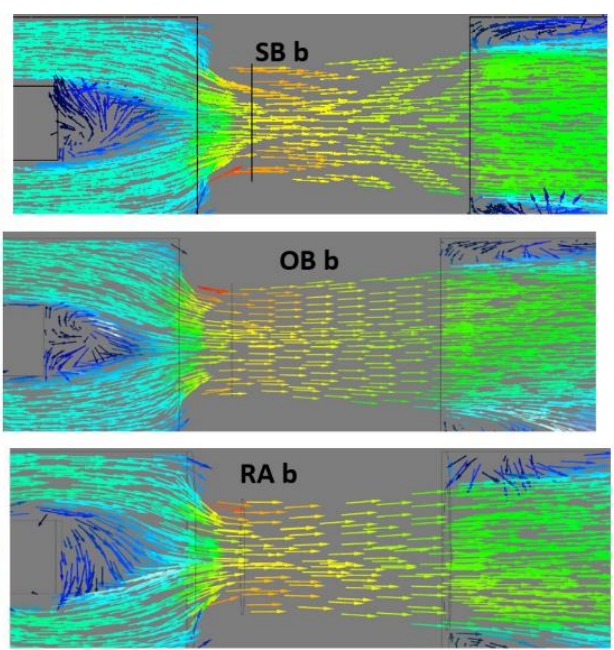

$\left.\mathrm{s}^{\wedge}-1\right]$

Figure 12 Velocity vector of individual fans (left a and right b) for symmetrical branches (SB, top), overlapped branches (OB, middle) and run around (RA, bottom)
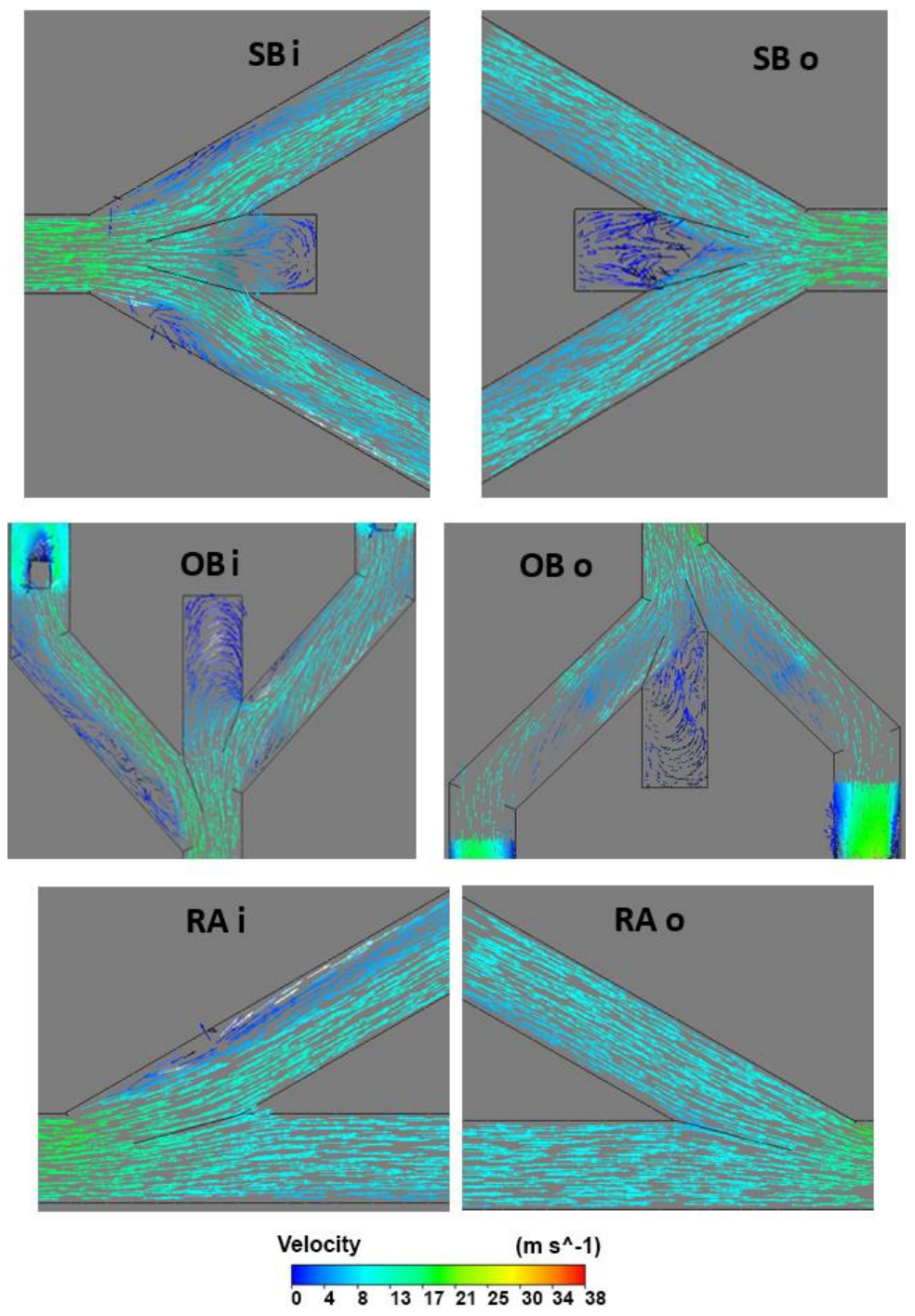

Figure 13 Velocity vector of individual fans for symmetrical branches (SB, top), overlapped branches (OB, middle) and run around (RA, bottom). Left inlet (i) and right outlet (o) 


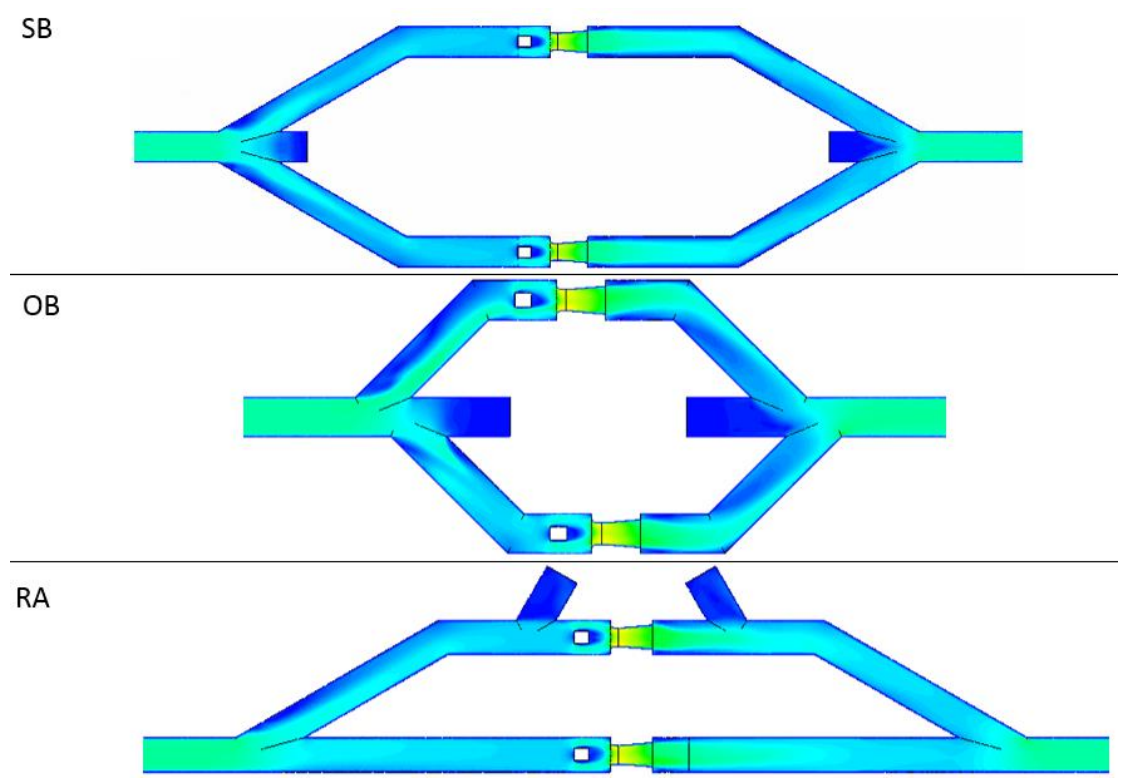

Figure 14 Velocity vector of individual fans (left and right) for symmetrical branches (SB, top), overlapped branches (OB, middle) and run around (RA, bottom)
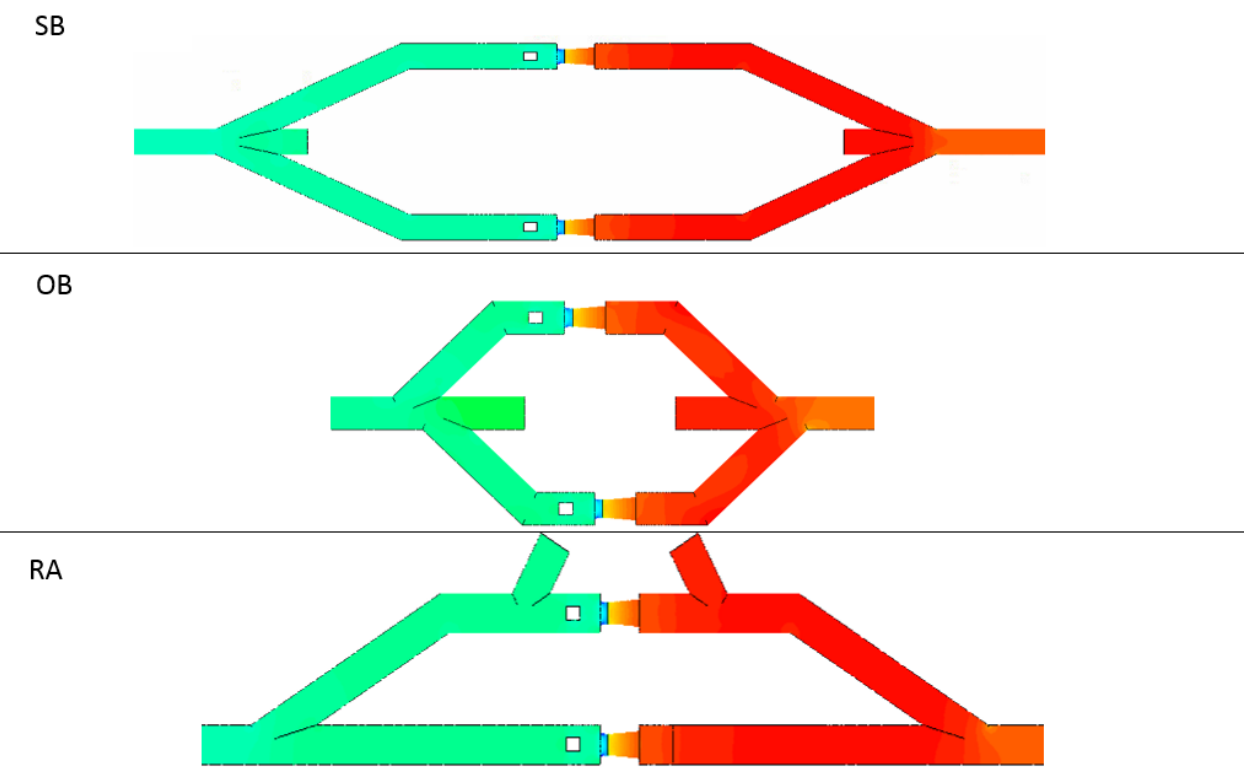

Figure 15 Static pressure vector of individual fans (left and right) for symmetrical branches (SB, top), overlapped branches (OB, middle) and run around (RA, bottom) 


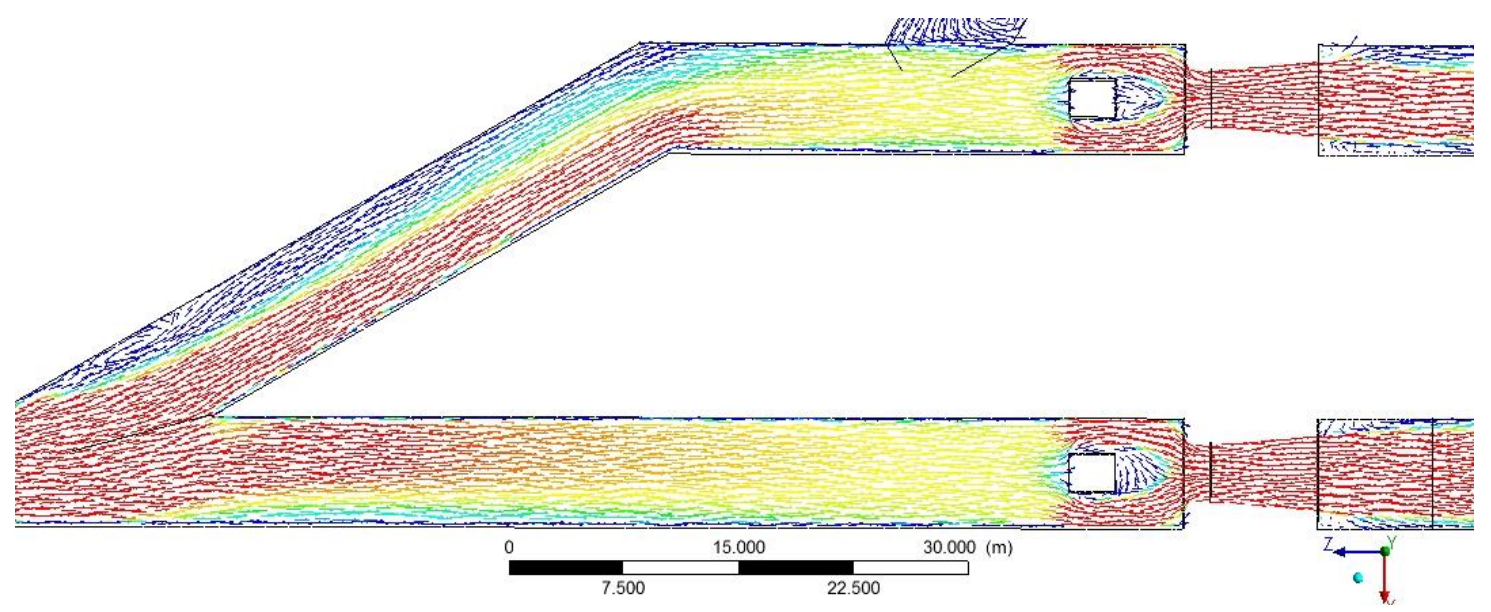

Figure 16 Velocity vectors on fan stations for run around configuration with an adjusted velocity scale to appreciate differences of velocities in the stream before fans

Overall, the resistance of the symmetrical branches arrangement is slightly higher than that of the overlapped branches circuit, although the latter has more acute angle bends and displaced joints and separations, which generate a more turbulent flow, as can be seen in Figures 12, 13 and 14. The reason for this is the $138 \mathrm{~m}$ shorter length of the overlapped branch configuration from split point until union point of the branches. As a result, the reduction in linear losses would more than compensate for the higher turbulent losses of the configuration of this station. As previously mentioned, these are mine site operating configuration geometries, and as such, the intent of this study was not to compare equal fan station lengths, but to determine which geometry delivered the best performance.

\subsection{Energy consumption analysis}

Due to more representative operation points of fan curves in the mid-resistance $\left(X_{\text {entry }}=0, X_{\text {outlet }}=6.5\right.$ ), this shall be analysed particularly. There are differences in the total resistance curves of the system between the different configurations, even though they were subjected to the same boundary and initial conditions, indicating that the configuration of the station influences the fan performance just like a singularity as expected. The resistance curves obtained for each of the stations, as given in Table 3, show that the run around configuration has the lowest resistance at $0.00201 \mathrm{~kg} \mathrm{~s} / \mathrm{m}^{8}$ and the symmetrical branch had the highest resistance at $0.00236 \mathrm{~kg} \mathrm{~s}^{2} / \mathrm{m}^{8}$, an increase of $3.48 \times 10-4 \mathrm{~kg} \mathrm{~s}^{2} / \mathrm{m}^{8}$ or $17 \%$. The overlap branch arrangement fell midway between these two arrangements.

Table 3 Ventilation system resistance operational points for studied fan ventilation station geometries

\begin{tabular}{|c|c|c|c|c|c|c|c|c|c|c|}
\hline \multicolumn{2}{|c|}{$x$} & \multicolumn{3}{|c|}{ SB } & \multicolumn{3}{|c|}{ OB } & \multicolumn{3}{|c|}{ RA } \\
\hline$X_{\text {inlet }}$ & $X_{\text {outlet }}$ & $\begin{array}{l}Q \\
\left(m^{3} / s\right)\end{array}$ & $\begin{array}{l}\mathrm{Ps} \\
(\mathrm{Pa})\end{array}$ & $\begin{array}{l}\text { R } \\
\left(\mathrm{kg} \mathrm{s}^{2} / \mathrm{m}^{8}\right)\end{array}$ & $\begin{array}{l}Q \\
\left(m^{3} / s\right)\end{array}$ & $\begin{array}{l}\mathrm{Ps} \\
(\mathrm{Pa})\end{array}$ & $\begin{array}{l}R \\
\left(\mathrm{~kg} \mathrm{~s}^{2} / \mathrm{m}^{8}\right)\end{array}$ & $\begin{array}{l}Q \\
\left(m^{3} / s\right)\end{array}$ & $\begin{array}{l}\mathrm{Ps} \\
(\mathrm{Pa})\end{array}$ & $\begin{array}{l}\text { R } \\
\left(\mathrm{kg} \mathrm{s}^{2} / \mathrm{m}^{8}\right)\end{array}$ \\
\hline 7.5 & 15 & 529 & 1,872 & 0.00668 & 525 & 1,866 & 0.00677 & 532 & 1,868 & 0.00661 \\
\hline 0 & 6.5 & 738 & 1,285 & 0.00236 & 750 & 1,221 & 0.00217 & 760 & 1,162 & 0.00201 \\
\hline 0 & 0 & 878 & 161 & 0.00021 & 868 & 241 & 0.00032 & 880 & 127 & 0.00016 \\
\hline
\end{tabular}


Figure 9 shows that the working range of the fan is dominated by a decreasing power with the flow rate. Table 4 shows the variation in total consumed power per two-fan station at different points of the fan curve across the different configurations. This table shows that RA consumes more energy than the other arrangement at low flow rates, but becomes the lowest energy user at high flow rates. If the annual consumption of these differences is quantified (Table 5) in terms of energy consumption, it can be seen that the run around station obtains a lower consumption with a slight decrease in its operating point, which translates into a saving of at least $268 \mathrm{MW}$ annually compared to the other two geometries.

Table 4 Ventilation station power consumption

\begin{tabular}{llllllll}
\hline & & SB & OB & RA & $\Delta($ RA-SB) & $\Delta($ RA-OB) & $\Delta($ SB-OB $)$ \\
\hline$X_{\text {inlet }}$ & $\boldsymbol{X}_{\text {outlet }}$ & $\begin{array}{l}\text { Hydraulic } \\
\text { power (kW) }\end{array}$ & $\begin{array}{l}\text { Hydraulic } \\
\text { power (kW) }\end{array}$ & $\begin{array}{l}\text { Hydraulic } \\
\text { power (kW) }\end{array}$ & $\Delta(\mathbf{k W})$ & $\Delta(\mathbf{k W})$ & $\Delta(\mathbf{k W})$ \\
\hline 7.5 & 15 & 991 & 980 & 993 & 2 & 14 & 11 \\
7.5 & 7 & 1,034 & 1,027 & 1,029 & -5 & 2 & 7 \\
0 & 6.5 & 949 & 916 & 883 & -65 & -32 & 33 \\
0 & 3 & 597 & 629 & 577 & -20 & -52 & -32 \\
0 & 0 & 141 & 209 & 112 & -30 & -97 & -68 \\
\hline
\end{tabular}

Table 5 Annual ventilation station power consumption

\begin{tabular}{llllllll}
\hline \multicolumn{7}{c}{$k W /$ year } & \multicolumn{1}{c}{} \\
\hline $\boldsymbol{X}_{\text {inlet }}$ & $\boldsymbol{X}_{\text {outlet }}$ & SB & OB & RA & $\Delta$ (RA-SB) & $\Delta$ (RA-OB) & $\Delta$ (SB-OB) \\
\hline 7.5 & 15 & $8,246,145$ & $8,151,862$ & $8,265,344$ & 19,199 & 113,482 & 94,283 \\
0 & 6.5 & $7,894,305$ & $7,618,895$ & $7,350,396$ & $-543,908$ & $-268,498$ & 275,410 \\
0 & 0 & $1,175,199$ & $1,737,739$ & 928,510 & $-246,690$ & $-809,229$ & $-562,540$ \\
\hline
\end{tabular}

\section{Conclusion}

This study presents an attempt to simulate and compare the performance of two-fan parallel stations, considering three different configurations or geometries. This allows one to determine the resistance and power consumption of each configuration, and to estimate their energy performance when delivering a certain airflow volume and pressure drop. It was determined that the run around configuration has the best performance at higher airflow volumes. The results presented in this study suggest that the initial theoretical recommendation of constructing two-fan parallel stations as symmetrically as possible should be reviewed on a case-by-case basis. The work developed in this study also suggests that the run around is ranked as the best-performing geometry, mainly due to the reduced shock losses and relatively short ventilation drift length of this configuration when compared to the other two. Additional work would be required to compare the three geometries at equivalent lengths of development, and to quantify if the impact in shock losses could be overcome by the savings of reduced developments. Prior to defining a fan station model, it is strongly recommended to set a CFD analysis of different options that considers geometrical, aerodynamic and economic aspects.

\section{Acknowledgement}

This work was supported by the Dicyt Research Project number 051515HC executed at Universidad de Santiago de Chile. 


\section{References}

Acuña, El, Hurtado, JP \& Wallace, KG 2014, 'A summary of the computational fluid dynamic application to the New Level Mine project of El Teniente', Proceedings of the 10th International Mine Ventilation Congress, The Mine Ventilation Society of South Africa, Johannesburg, pp 91-97.

Hurtado, JP \& Acuña, El 2015, 'CFD analysis of 58 Adit main fans parallel installation for the 2015-2019 underground developments of the new level mine project', Applied Thermal Engineering, vol. 90, pp. 1109-1118.

Isidro, D, Torno, S, Toraño, J, Menendez, M \& Gent, M 2010, 'A practical use of CFD for ventilation of underground works', Tunnelling and Underground Space Technology, vol. 26, no. 1, pp. 189-200.

McPherson, MJ 2009, Subsurface Ventilation and Environmental Engineering, Chapman \& Hall, London.

Versteeg, HK \& Malalasekera, W 1995, An introduction to Computational Fluid Dynamics, Longman Scientific \& Technical, Essex. 